\title{
Angiotensin-(1-7)-induced plasticity changes in the lateral amygdala are mediated by COX-2 and NO
}

\author{
Doris Albrecht \\ Institute of Neurophysiology, Charité-Universitätsklinikum Berlin, 10117 Berlin, Germany
}

\begin{abstract}
It is known from studies outside the brain that upon binding to its receptor, angiotensin-(1-7) elicits the release of prostanoids and nitric oxide (NO). Cyclooxygenase (COX) is a key enzyme that converts arachidonic acid to prostaglandins. Since there are no data available so far on the role of COX-2 in the amygdala, in a first step we demonstrated that the selective COX-2 inhibitor NS-398 significantly reduced the probability of long-term potentiation (LTP) induction in the lateral nucleus of the amygdala. Similarly, in COX-2 ${ }^{-1-}$ mice, LTP induced by external capsule (EC) stimulation was impaired. Second, we evaluated the action of angiotensin-(1-7) in the amygdala. In wild-type mice, angiotensin-(1-7) increased LTP. This LTP-enhancing effect of Ang-(1-7) was not observed in COX-2+l- mice. However, in COX-2-1- mice, Ang-(1-7) caused an enhancement of LTP similar to that in wild-type mice. The NO synthetase inhibitor L-NAME blocked this angiotensin-(1-7)-induced increase in LTP in COX-2-lmice. Low-frequency stimulation of external capsule fibers did not cause long-term depression (LTD) in drug-free and angiotensin-(1-7)-treated brain slices in wild-type mice. In contrast, in COX-2-1- mice, angiotensin-(1-7) caused stable LTD. Increasing NO concentration by the NO-donor SNAP also caused LTD in wild-type mice. Our study shows for the first time that LTP in the amygdala is dependent on COX-2 activity. Moreover, COX-2 is involved in the mediation of angiotensin-(1-7) effects on LTP. Finally, it is recognized that there is a molecular cross-talk between COX-2 and NO that may regulate synaptic plasticity.
\end{abstract}

Long-term potentiation (LTP) and long-term depression (LTD) are two forms of activity-dependent synaptic plasticity that are thought to be involved in learning and memory. The reninangiotensin system does not only play a critical role in blood pressure control but is also involved in learning and memory mechanisms (Arima and Ito 2001; Wright et al. 2002; von Bohlen und Halbach and Albrecht 2006). In addition to angiotensin II (Ang II), angiotensin-(1-7) [Ang-(1-7)] may also have important biological activities in the brain. We have recently shown that Ang-(1-7) enhances LTP in the CA1 region of the hippocampus (Hellner et al. 2005). Our studies with AT1 receptor antagonists and a selective Ang-(1-7) receptor antagonist demonstrated the existence of a distinct Ang-(1-7) receptor in the brain, the Gprotein-coupled receptor Mas, encoded by the Mas protooncogene. We have also shown that the genetic deletion of this receptor abolishes the Ang-(1-7)-induced enhancement of LTP (Hellner et al. 2005). It is known that Ang II acts on and through the amygdala to stimulate thirst and sodium appetite (Stellar 1993; Johnson and Thunhorst 1997). We could show that Ang II not only changed neuronal activity in the amygdala of normotensive and hypertensive rats (Albrecht et al. 2000), but also suppressed LTP in the lateral nucleus of the amygdala (LA) (von Bohlen und Halbach and Albrecht 1998). We were now interested in testing whether Ang-(1-7) also causes changes in LA-LTP. It is known that upon binding to its receptor, Ang-(1-7) elicits the release of NO and prostanoids (Santos et al. 2000). Ang-(1-7) is able to activate endothelial NO synthetase (e-NOS). This is in line with the reported vasorelaxant effect of Ang-(1-7) on precontracted coronary arteries (Brosnihan 1998), which could be blocked by pretreatment with NOS inhibitors. Furthermore, in rabbit aortic smooth muscle cells, Ang-(1-7) stimulates prostacyclin synthesis by promoting the release of arachidonic acid from tissue lipids via activation of CaM kinase II, which, in turn, via mitogen-activated protein kinase enhances cytosolic phosholi-

E-mail doris.albrecht@charite.de; fax (030) 450528962.

Article is online at http://www.learnmem.org/cgi/doi/10.1101/Im.425907. pase $A_{2}$ activity (Muthalif et al. 1998). Cyclooxygenase-2 (COX2 ) is an essential enzyme for prostaglandin synthesis from arachidonic acid. Recently, evidence has been accumulated indicating that there is a constant cross-talk between $\mathrm{NO}$ and prostaglandin release that occurs at many levels. The final effect of this modulatory activity is not univocal, since endogenous NO as well as NO donors have been found to switch on/off the COX pathway, depending on the basal levels of NO released, by the cell type in which prostaglandin biosynthesis is generated and by the intensity of the stimulus used for prostaglandin release (Mollace et al. 2005). It is known that cyclooxigenases are implicated in some neurologic disorders, including stroke (Warner and Mitchell 2004), epilepsy (Hashimoto et al. 1998; Takemiya et al. 2003), Parkinson's (Feng et al. 2003; Vijitruth et al. 2006), and Alzheimer's disease (O'Banion 1999; Giovannini et al. 2003; Ho et al. 2006).

Recent evidence that COX-2 is regulated by synaptic activity (Yamagata et al. 1993; Caggiano et al. 1996; Miettinen et al. 1997) implies participation of COX-2 in neuronal plasticity. It has been shown that selective COX-2 inhibitors significantly reduced postsynaptic membrane excitability, back-propagating dendritic action potential-associated $\mathrm{Ca}^{2+}$ influx, and LTP induction in hippocampal dentate granule neurons and CA1 neurons, while COX-1 inhibitors were ineffective (Chen et al. 2002; Murray and O'Connor 2003; Slanina et al. 2005). In addition, recent behavioral data indicate that COX-2 is a required biochemical component mediating the consolidation of hippocampusdependent memory (Teather et al. 2002). The functional significance of COX-2 in the amygdala is unclear, although its expression is high (Kaufmann et al. 1996). A comparably high packing density of COX-2-positive neurons also has been observed in the LA (Bidmon et al. 2000). The question arises whether inhibition of COX-2 with NS-398 will influence LA-LTP evoked upon stimulation of EC fibers. To further assess the role of COX-2 in Ang(1-7)-induced plasticity changes, we analyzed Ang-(1-7)-induced responses in brain slices derived either from COX-2-deficient (homozygous and heterozygous) mice or from wild-type controls. 


\section{Results}

\section{COX-2 affects basal transmission, short-term and long-term potentiation}

To examine the effect of COX-2 on synaptic function in the amygdala, we first tested input/output curves in slices derived from heterozygous COX-2-deficient $(+/-)$ and homozygous COX-2-deficient $(-/-)$ mice and compared them with those from wild-type mice $(+/+)$. As shown in Figure 1A, input/output curves did not show significant differences between the groups taken as a whole. However, there was a significant difference between wild-type and heterozygous COX-2-deficient mice at higher current intensities $(400-600 \mu \mathrm{A}, P<0.03)$.

To investigate pre- versus postsynaptic sites of action, we

A

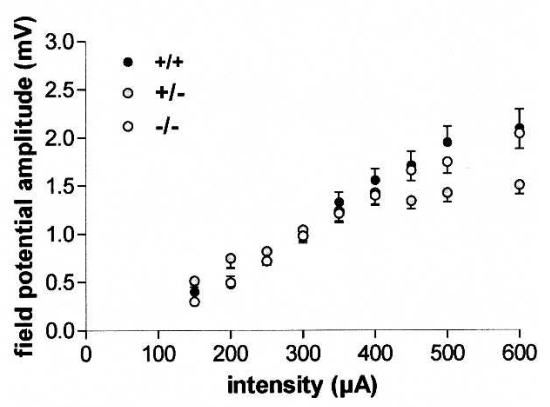

B
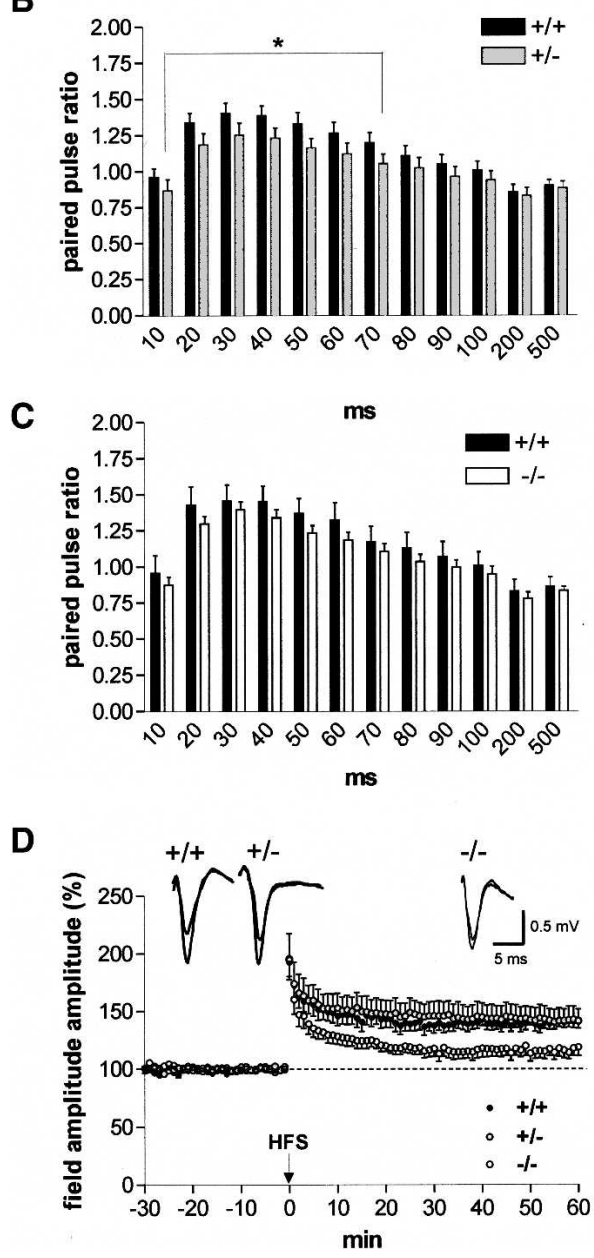

used a paired-pulse facilitation protocol consisting of two stimuli of the same intensity delivered at different time intervals. As shown in Figure 1B, in heterozygous COX-2-deficient mice $(n=31)$, the paired-pulse facilitation was significantly weaker at intervals from 10 to $70 \mathrm{msec}$ as compared to controls $(n=30$, $P<0.04)$. An insignificant reduction of paired-pulse facilitation was seen in homozygous COX-2-deficient mice $(n=39)$ in comparison with their wild-type littermates ( $n=18$; Fig. 1C).

In response to high-frequency stimulation (HFS) of external capsule fibers, a similar potentiation of field potential amplitudes in the LA was observed both in wild-type and heterozygous COX2 -deficient mice $(+/+, 141.0 \% \pm 5.5 \%[n=9]$ vs. $+/-$, $141.8 \% \pm 10.8 \%[n=8]$; Fig. 1D). The magnitude of LTP did not differ significantly between these two animal groups. In contrast, the magnitude of LA-LTP was significantly decreased in homozygous COX-2-deficient mice relative to wild-type controls $(-/-, 116.6 \% \pm 6.5 \%[n=8]$; Fig. 1D).

To further determine whether COX-2 participates in LTP of LA neurons, brain slices derived from wild-type mice were pretreated with NS-398 $\left(10 \mu \mathrm{M}\right.$, a concentration above IC $_{50}$ for COX-2 but below $\mathrm{IC}_{50}$ for COX-1) (Vane et al. 1998) for $30 \mathrm{~min}$ prior to determination of the second input/output curve and paired-pulse facilitation. Whereas input/output curves did not show significant differences $(n=13$; Fig. 2A), paired-pulse facilitation was impaired in NS-398-treated slices in comparison with controls $(P<0.0005$ [ $n=13]$; Fig. 2B). Inhibition of COX-2 with NS-398 resulted in the complete suppression of LTP in comparison with $0.1 \%$ DMSO-treated slices (NS-398, 105.3\% $\pm 2.9 \%$ $[n=7]$ vs. DMSO, $139.1 \% \pm 4.6 \%[n=7]$; Fig. $2 C)$. Thus, the experiments in COX-2 knockout mice as well as the experiments with pharmacological inhibition of COX-2 activity show that COX-2 is involved in mechanisms regulating synaptic plasticity in the amygdala.

\section{Decrease in paired-pulse potentiation after induction of LTP}

Whether the locus of expression of LA-LTP is presynaptic or postsynaptic is still debatable. An increase in the probability of release of glutamate during LTP suggests a presynaptic involvement. As shown in Figure 3A, in wild-type mice, the plot of the ratios of second to first responses at varying interpulse intervals recorded $60 \mathrm{~min}$ after induction of LTP indicates that responses in the LA were significantly less facilitated throughout interpulse intervals of 10-100 msec than control responses recorded before the application of HFS $(n=21, P<0.04)$. Thus, we observed LTP-

Figure 1. COX-2 influences excitability and plasticity in the lateral nucleus of the amygdala (LA). (A) Input/output curves, which demonstrate differences in field potential amplitudes between homozygous, heterozygous COX-2-deficient mice, and their wild-type littermates. Note a significant difference between wild-type and heterozygous COX2-deficient mice at higher current intensities $(400-600 \mu \mathrm{A}, P<0.03)$. (B) Paired-pulse ratios of field potential amplitudes in the LA in slices derived from (black bars) wild-type $(+/+; n=30)$ and (gray bars) heterozygous COX-2-deficient $(+/-; n=31)$ mice. At interstimulus intervals from 10 to $70 \mathrm{msec}$, a significant reduction of paired-pulse facilitation was found in heterozygous COX-2-deficient mice $(P<0.04)$. (C) Paired-pulse ratios of field potential amplitudes in the LA in slices derived from (black bars) wild-type (+/+; $n=18)$ and (white bars) homozygous COX-2-deficient $(-/-; n=39)$ mice. $(D)$ High-frequency stimulation (HFS) of external capsule fibers elicited a reduced magnitude of LA-LTP in homozygous COX-2-deficient mice $(-/-; n=8)$ in comparison with heterozygous COX-2-deficient mice $(+/-; n=8)$ and their wild-type littermates $(+/+$; $n=9$ ). Representative traces were recorded $5 \mathrm{~min}$ prior to tetanus and 60 min after tetanus in the lateral nucleus of the amygdala. Application of high-frequency stimulation (HFS; $2 \times 100 \mathrm{~Hz}$, duration $1 \mathrm{sec}$, interval 30 sec) at time 0 . Data points represent averaged amplitudes (mean \pm SEM) normalized with respect to baseline values. 
A

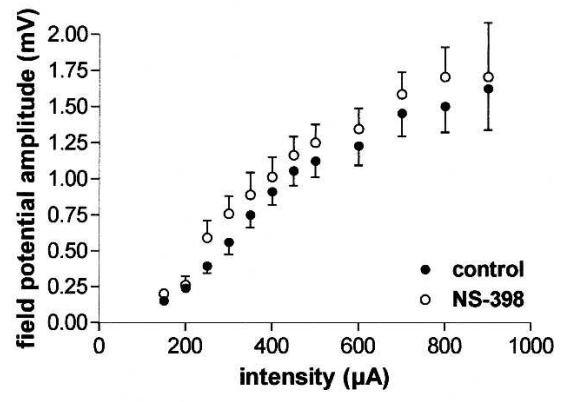

B

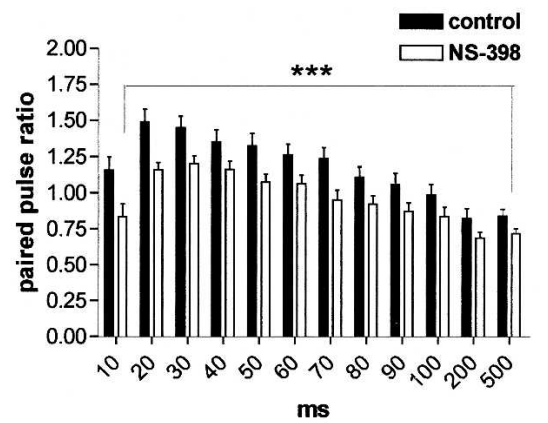

C

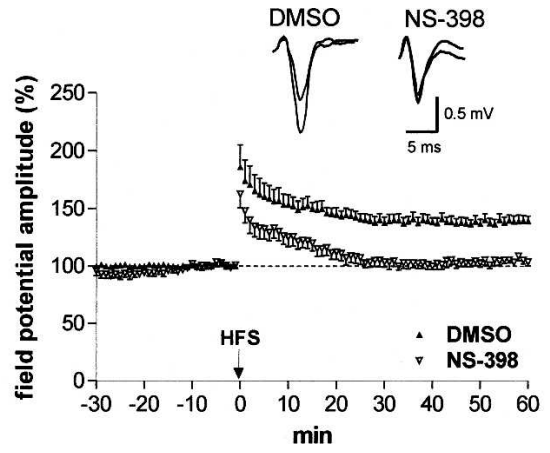

Figure 2. Action of the selective COX-2 inhibitor NS-398 on excitability, paired-pulse facilitation, and LTP. ( $A$ ) Input/output curves did not show significant changes between control recording and after NS-398 application $(10 \mu \mathrm{M} ; n=13)$. (B) NS-398 $(10 \mu \mathrm{M})$ caused an impairment of paired-pulse facilitation $(n=13)$. (C) NS-398 $(n=7)$ significantly suppressed LA-LTP in wild-type mice in comparison to DMSO-treated controls $(n=7)$. Representative traces were recorded 5 min prior to tetanus and 60 min after tetanus in the lateral nucleus of the amygdala. Application of high-frequency stimulation (HFS; $2 \times 100 \mathrm{~Hz}$, duration $1 \mathrm{sec}$, interval $30 \mathrm{sec}$ ) at time 0 . Data points represent averaged amplitudes (mean \pm SEM) normalized with respect to baseline values.

induced significant decrease in PPF in LA neurons derived from wild-type mice after HFS of external capsule fibers similar to recent data obtained in coronal slices (Tsvetkov et al. 2002; Humeau et al. 2003). Both in heterozygous $(n=25, P<0.001)$ and homozygous COX-2-deficient mice $(n=21, P<0.001)$, a significant decrease in paired-pulse facilitation was also obtained after induction of LTP over the range of interpulse intervals from 10 to $200 \mathrm{msec}$ (Fig. 3B,C). In contrast, paired-pulse facilitation recorded $60 \mathrm{~min}$ after induction of LTP was not significantly changed in NS-398-treated slices when compared to those recorded at the beginning of the recording (Fig. 3D). Therefore, NS-398-induced suppression of LA-LTP did not result in changes in paired-pulse facilitation recorded $60 \mathrm{~min}$ after tetanic stimulation.

\section{Ang-(1-7) did not affect basal transmission, but enhanced paired-pulse facilitation and LA-LTP in a concentration-dependent fashion}

As shown in Figure 4A, low concentrations $(0.01 \mu \mathrm{M})$ of Ang-(1$7)$ did not change input/output curves $(P>0.05)$. However, paired-pulse facilitation was significantly enhanced by Ang-(1-7) throughout interpulse intervals of $40-90 \mathrm{msec}$ in comparison with drug-free controls ( $n=17$; Fig. 4B). Higher concentrations of Ang-(1-7) caused reduction of PPF (data not shown). Similarly, the effect of Ang-(1-7) on LA-LTP varied in a dose-dependent fashion, with higher doses of Ang-(1-7) (up to $5 \mu \mathrm{M}$ ) causing an inhibition of LA-LTP similar to that observed in the hippocampus (Hellner et al. 2005) caused by the stimulation of angiotensin AT1 receptors (data not shown). Since the specific angiotensin AT1 receptor antagonist, losartan, was able to block this suppression of LA-LTP, these data support our results in the hippocampus. Thus, Ang-(1-7) stimulates AT1 receptors when used in high concentrations. Therefore, we reduced the concentration of Ang(1-7) to get Ang-(1-7) receptor-specific effects. In contrast to our dose-dependent results in the hippocampus (Hellner et al. 2005), bath application of $0.5 \mu \mathrm{M}$ Ang-(1-7) did not change the magnitude of LA-LTP in comparison with drug-free controls $(136.4 \% \pm 6.3 \%[n=8]$ vs. $141.0 \% \pm 5.5 \%[n=9])$. However, low $(0.01 \mu \mathrm{M})$ concentrations of Ang-(1-7) caused an enhancement of LA-LTP (Fig. 4C). Mean field potential responses were significantly higher in Ang-(1-7)-treated slices (159.1\% \pm 9.7\%; $n=8, P<0.001)$ than in drug-free control slices derived from wild-type mice. Such an LTP-enhancing effect of Ang-(1-7) was always found in the hippocampus with concentrations of $\leq 5 \mu \mathrm{M}$ when using high-frequency stimulation (Hellner et al. 2005).

The development of a selective Ang-(1-7) antagonist (A779) provided evidence for an Ang-(1-7) receptor distinct from the classical angiotensin receptors (Santos et al. 1994). As shown in Figure 4D, the Ang-(1-7)-induced enhancement of LA-LTP could be blocked by the specific Ang-(1-7) receptor antagonist A779 $(140.6 \% \pm 6.9 \% ; n=8)$. Therefore, Ang-(1-7) facilitates the induction of LA-LTP through a specific Ang-(1-7) receptor. Our recent findings in the hippocampus (Hellner et al. 2005) are supported now by these data obtained in the amygdala, suggesting that this peptide is an endogenous ligand for the G-proteincoupled receptor Mas. This conclusion was supported by the observation that Ang-(1-7) did not change LA-LTP in Mas knockout mice (data not shown).

The mechanism of the LTP-enhancing effect by Ang-(1-7) is unclear, but it is known from different Ang-(1-7) studies outside the CNS that NO is involved in the mediation of Ang-(1-7) effects besides COX-2. In the CNS, NO is increasingly being considered as a trans-synaptic retrograde messenger, involved in neuronal plasticity. Therefore, we tested the unspecific inhibitor of the NOS L-NAME. In the presence of L-NAME, Ang-(1-7) was not able to affect the magnitude of HFS-induced LA-LTP $(138.9 \% \pm 4.2 \%$ $[n=10]$; Figs. 4D, 5C). These results show that NO is also involved in Ang-(1-7)-mediated effects in the brain. The changes in paired-pulse facilitation suggest a presynaptic component.

\section{Ang-(1-7) did not alter LA-LTP in heterozygous COX-2-deficient mice, but enhanced LA-LTP in homozygous COX-2-deficient mice}

To assess the significance of COX-2 for the Ang-(1-7)-induced changes in synaptic plasticity in the amygdala, we administered Ang-(1-7) to COX-2-deficient mice. In heterozygous COX-2deficient mice, Ang-(1-7) did not show any effect on HFS-induced LTP-neither at the concentration of $0.5 \mu \mathrm{M}$ nor at $0.01 \mu \mathrm{M}$ $(143.2 \% \pm 6.2 \%[n=7]$ vs. $140.8 \% \pm 4.6 \%[n=7])$ (Fig. $5 \mathrm{~A})$. 
A
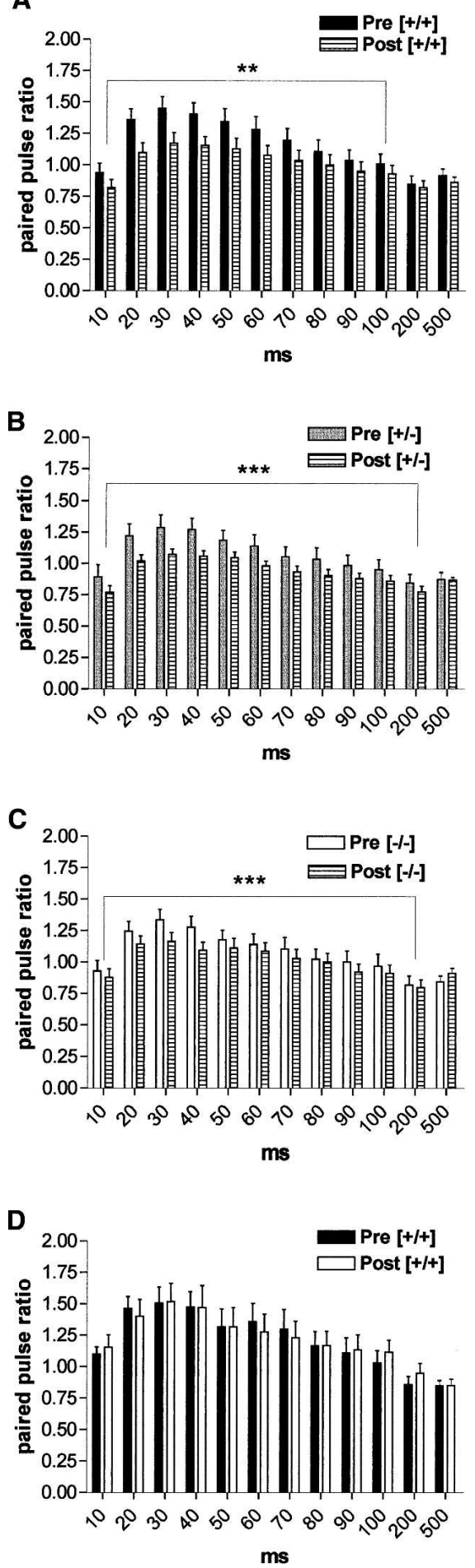

Figure 3. Interaction between paired-pulse facilitation and LTP. ( $A$ ) The plot of the ratios of second to first responses at varying interpulse intervals recorded $60 \mathrm{~min}$ after induction of LTP (Post) in wild-type mice indicates that responses in the LA were significantly less facilitated throughout interpulse intervals of $10-100 \mathrm{msec}$ than control responses recorded before the application of HFS (Pre) $(n=21, P<0.04)$. (B,C) Both in heterozygous $(n=25, P<0.001)$ and homozygous $(n=21, P<0.001)$ COX-2deficient mice, a significant decrease in paired-pulse facilitation was obtained after induction of LTP over the range of interpulse intervals from 10 to 200 msec. (D) In slices in which NS-398 blocked the induction of LTP, paired-pulse facilitation recorded 60 min after tetanic stimulation did not differ from that recorded before washing in NS-398.
This result lets us assume that COX-2 is also involved in the mediation of Ang-(1-7) effects on synaptic plasticity in the amygdala.

Surprisingly, in homozygous COX-2-deficient mice, Ang-(17) elicited an enhancement of LA-LTP $[166.7 \% \pm 6.7 \%[n=9]$ at $0.01 \mu \mathrm{M}$ Ang-(1-7)] similar to that induced in wild-type animals. The Ang-(1-7)-induced change in field potential amplitude in homozygous COX-2-deficient mice during the last 6 min of the recording was significantly larger than that of heterozygous COX-2-deficient mice $(P<0.001)$. Obviously, in knockout animals, compensatory changes in other transmitter systems occur during the fetal period. The enhancement of LA-LTP induced by Ang-(1-7) in homozygous COX-2-deficient mice was blocked by L-NAME $(135.3 \% \pm 11.5 \%[n=7]$; Fig. 5B,C). This finding suggests that compensatory changes in the NO system in COX-2 knockout animals preserved synaptic plasticity to levels similar to Ang-(1-7)-induced changes in wild-type mice.

\section{Ang-(1-7) established LFS-induced LTD in homozygous COX-2-deficient mice}

In agreement with our previous results obtained by intracellular and extracellular recordings in rats (Kaschel et al. 2004), we found that prolonged low-frequency stimulation (LFS) of external capsule fibers ( $1 \mathrm{~Hz}$ for $15 \mathrm{~min}$ ) did not induce LTD in the LA of slices derived from wild-type mice. LFS had also no significant effect on field potential amplitude in Ang-(1-7)-treated slices derived from wild-type mice $(112.1 \% \pm 5.4 \%[n=6]$ vs. $102.7 \% \pm 7.3 \%[n=7], P>0.05$; Fig. 6A,D). However, LFS delivered in the presence of $0.01 \mu \mathrm{M}$ Ang-(1-7) reliably induced LTD in homozygous COX-2-deficient mice $(107.6 \% \pm 8.2 \%[n=7]$ vs. $68.5 \% \pm 11.6 \%[n=5], P<0.01$; Fig. $6 \mathrm{~B}, \mathrm{D})$. Thus, stable LTD was only induced by Ang-(1-7) in COX-2 knockout mice. To test the hypothesis that an up-regulation of NO concentration in homozygous COX-2-deficient mice might be responsible for plasticity changes in the amygdala, we tried to enhance NO concentration by SNAP in wild-type mice. As shown in Figure 6, C and $\mathrm{D}$, incubation of slices with SNAP $(100 \mu \mathrm{M})$ caused a longlasting weak depression of activity in response to LFS $(89.5 \% \pm 2.7 \%[n=7])$. Thus, the increase in NO concentration seems to support the development of LTD in the lateral amygdala.

\section{Discussion}

Our data provide the first evidence that COX-2 contributes to plasticity changes in the amygdala. We have shown that the COX-2 inhibitor NS-398 blocks LTP in the lateral amygdala. The involvement of COX-2 in the mediation of LA-LTP is supported by the decrease in LA-LTP in animals lacking the inducible enzyme COX-2. Previous studies have demonstrated a strong induction of neuronal COX-2 in response to depolarization (Yamagata et al. 1993; Caggiano et al. 1996; Miettinen et al. 1997). COX-2 is dramatically and transiently induced in neurons of the amygdala in response to NMDA receptor activation (Andreasson et al. 2001). Recently we have shown that LA-LTP is NMDA-dependent when EC stimulation is applied in horizontal slices (Drephal et al. 2006). The external capsule contains amygdala afferences from higher-order sensory cortices (deOlmos et al. 1985). In horizontal slices, EC stimulation also activates excitatory afferences from the lateral entorhinal and perirhinal cortex that synapse in the lateral and the basolateral nucleus of the amygdala (von Bohlen und Halbach and Albrecht 2002).

Our result, regarding a reduced LA-LTP in COX-2 knockout mice, is supported by several studies conducted on hippocampal slices. These studies have shown that inhibition of COX-2 activity impaired LTP in the hippocampus (Chen et al. 2002; Slanina 
et al. 2005), consistent with cognitive deficits (Teather et al. 2002; Rall et al. 2003). Moreover, COX-2 transgenic mice have been shown to develop deficits in spatial memory (Andreasson et

A

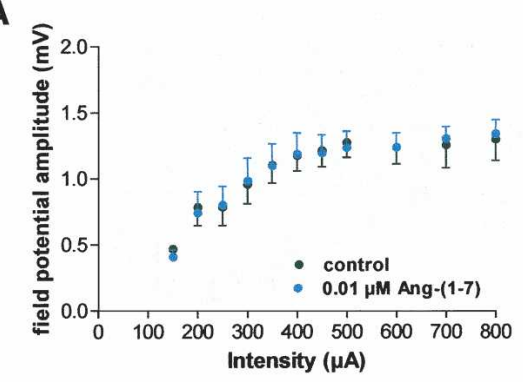

B

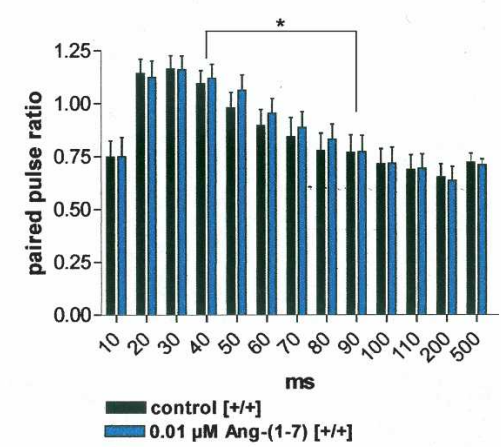

C

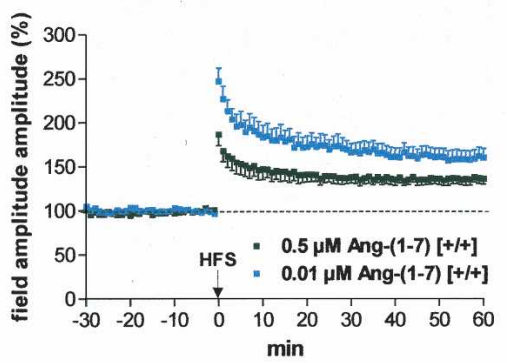

D

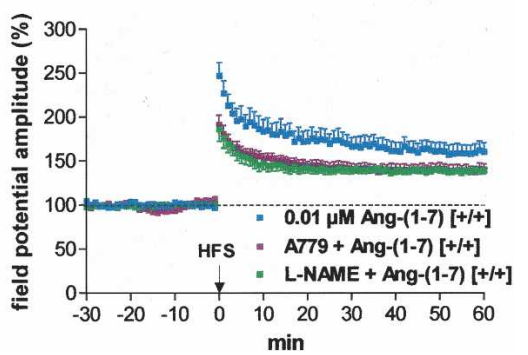

Figure 4. Dose-dependent effects of angiotensin-(1-7) on excitability and plasticity in the LA of slices derived from wild-type mice. (A) Ang-(17) $(0.01 \mu \mathrm{M})$ did not change input/output curves significantly; (B) (blue bars) $0.01 \mu \mathrm{M}$ Ang-(1-7) enhanced paired-pulse facilitation throughout interpulse intervals of $40-90 \mathrm{msec}(n=17)$; (C) $0.5 \mu \mathrm{M}$ Ang-(1-7) $(n=8)$ did not change the magnitude of LA-LTP in comparison to drug-free controls (see Fig. 1D), whereas $0.01 \mu \mathrm{M}$ significantly increased LA-LTP $(n=8)$. (D) A779 $(0.01 \mu \mathrm{M})$, a specific Ang-(1-7) receptor antagonist, blocked the LTP-enhancing effect of Ang-(1-7) $(n=8)$. The unspecific inhibitor of the NO system L-NAME $(200 \mu \mathrm{M})$ also blocked the Ang-(17)-mediated effect $(n=10)$. For comparison, the effect of $0.01 \mu \mathrm{M}$ Ang$(1-7)$ on the induction of LTP is also presented. $(C, D)$ Application of high-frequency stimulation (HFS; $2 \times 100 \mathrm{~Hz}$, duration $1 \mathrm{sec}$, interval 30 sec) at time 0 . Data points represent averaged amplitudes (mean \pm SEM) normalized with respect to baseline values.
A

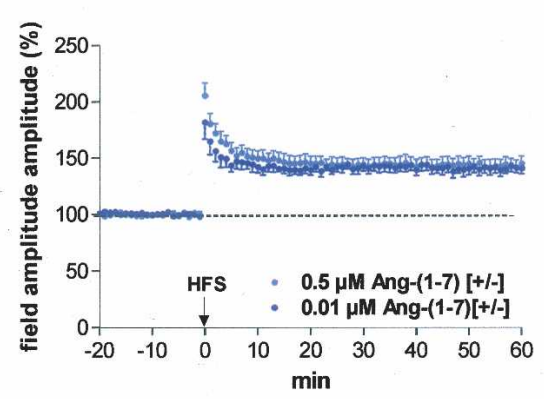

B

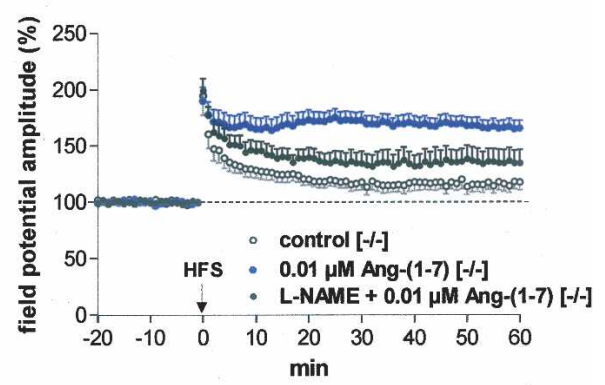

C

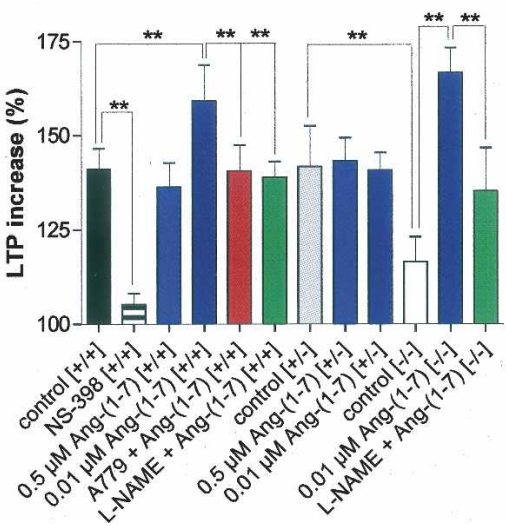

Figure 5. Effects of Ang-(1-7) on LTP in COX-2-deficient mice. (A) In heterozygous COX-2-deficient mice (+/-), Ang-(1-7) neither at $0.5 \mu \mathrm{M}$ $(n=7)$ nor at $0.01 \mu \mathrm{M}(n=7)$ was able to change the magnitude of LA-LTP in comparison to drug-free controls. $(B)$ In homozygous COX-2deficient mice $(-/-), 0.01 \mu \mathrm{M}$ Ang-(1-7) $(n=9)$ elicited a significant enhancement of LA-LTP. This enhancement of LTP could be blocked by $200 \mu \mathrm{M} \mathrm{L-NAME}(n=7)$. For comparison, the control LTP recorded in COX-2 $2^{-1-}$ mice is also presented. $(A, B)$ Application of high-frequency stimulation (HFS; $2 \times 100 \mathrm{~Hz}$, duration $1 \mathrm{sec}$, interval $30 \mathrm{sec}$ ) at time 0 . Data points represent averaged amplitudes (mean \pm SEM) normalized with respect to baseline values. (C) Bar histogram of data points shown in Figures 3 and 4, as averaged 55-60 min after HFS and normalized with respect to baseline (mean \pm SEM). Significant differences are indicated; $\left({ }^{* *}\right) P<0.001$.

al. 2001). In our study, the impaired LTP in the amygdala seen in COX-2-ablated mice was likely due to altered gene expression as a result of aberrant metabolism of arachidonic acid in the absence of the inducible isozyme of COX. Arachidonic acid selectively inhibits the transient A-type $\mathrm{K}^{+}$current in hippocampal neurons (Bittner and Muller 1999). In addition, it has been shown that COX-2 inhibition enhances inhibitory GABAergic synaptic transmission (Vaughan 1998). In this way, LA-LTP also might be suppressed in homozygous COX-2-deficient mice. The reduced paired-pulse facilitation in heterozygous COX-2deficient mice and in NS-398-treated mice suggests the involvement of presynaptic mechanisms. The insignificant reduction of 
A

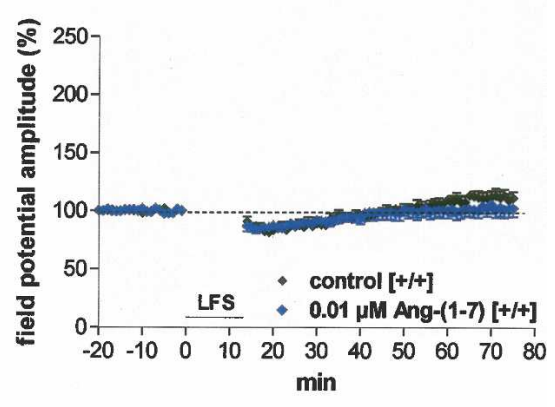

B

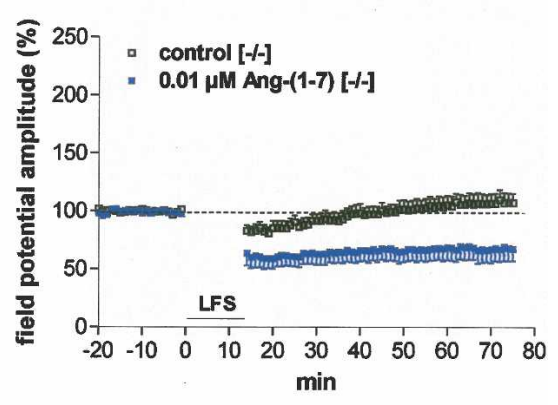

C

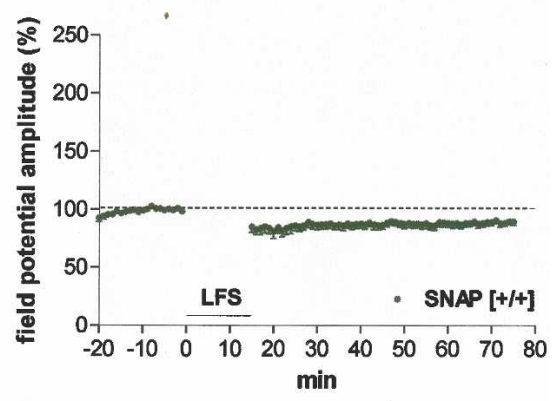

D

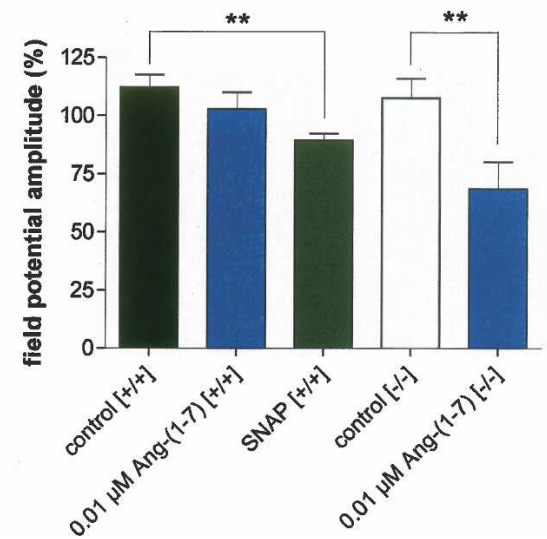

Figure 6. Effects of $0.01 \mu \mathrm{M}$ Ang-(1-7) on low-frequency stimulation (LFS) induced activity change in the LA. ( $A$ ) LFS caused a significant long-term depression (LTD) neither in drug-free controls $(n=6)$ nor in Ang-(1-7)-treated slices $(n=7)$ derived from wild-type mice $(+/+)$. (B) In homozygous COX-2-deficient mice (-/ -$), 0.01 \mu \mathrm{M}$ Ang-(1-7) elicited a significant, long-lasting reduction of field potential amplitudes $(n=5)$. In contrast, no LTD was observed in drug-free homozygous COX-2-deficient slices $(n=7)$. (C) SNAP (NO donor, $100 \mu \mathrm{M}$ ) induced a weak LTD in wild-type mice. $(D)$ Bar histogram of data points shown in Figure 5A-C, as averaged 55-60 min after LFS and normalized with respect to baseline (mean \pm SEM). Significant differences are indicated; $\left.{ }^{* *}\right) P<0.001$.

paired-pulse facilitation in homozygous COX-2-deficient mice might be due to compensatory changes during development in this mouse strain. COX-2, or rather its downstream product, may act as a retrograde signal mediating presynaptically-expressed plasticity in the LA. In this way, the impairment of LTP in homozygous COX-2-deficient mice could be also explained by a reduced glutamate release. Studies in coronal slices suggest the involvement of presynaptic mechanisms in EC-induced LA-LTP (Humeau et al. 2003). The reduction of paired-pulse facilitation 60 min after tetanic stimulation of external capsule fibers in controls supports this view for horizontal slices. Although the HFSinduced increase in field potential amplitudes in COX-2 $2^{-1-}$ is small, nevertheless an impairment of paired-pulse facilitation after tetanic stimulation was also observed in this mouse strain. In contrast, after complete depression of LTP caused by NS-398, no changes were observed in paired-pulse facilitation $1 \mathrm{~h}$ after tetanic stimulation.

Our data in heterozygous mice indicate that COX-2 is involved in mediation of the LTP-enhancing effect of Ang-(1-7) shown here for the first time in the amygdala. Similar to the data obtained in the hippocampus (Hellner et al. 2005), Ang-(1-7) enhances LA-LTP via the Mas receptor, whereas higher concentrations of Ang-(1-7) also act on angiotensin AT1 receptors. Stimulation of angiotensin AT1 receptors by high concentrations of Ang-(1-7) caused an inhibition of LA-LTP. A suppression of LA-LTP was also shown earlier for angiotensin II (von Bohlen und Halbach and Albrecht 1998). Angiotensin II also depresses LTP in the hippocampus (Denny et al. 1991; Armstrong et al. 1996). Therefore, Ang-(1-7) at low concentrations provokes plasticity changes, being antagonistic to stimulation of AT1 receptors.

Whereas Ang-(1-7) did not change the magnitude of LA-LTP because of the limited COX-2 activity in heterozygous mice, in homozygous COX-2-deficient mice, Ang-(1-7) caused a strong enhancement of LA-LTP. Since we undertook this study to test the hypothesis whether COX-2 is involved in the mediation of the effects of Ang-(1-7) on plasticity in the amygdala, these results were not expected. We suppose that compensatory changes in the fetal period may account for the Ang-(1-7) effects seen in homozygous COX-2-deficient mice. Since it has been found that COX-2 is modulated by NO (Salvemini et al. 1993), we tested the effect of the unspecific inhibitor of NOS, L-NAME. Blockade of NOS activity by L-NAME abolished the effect of Ang-(1-7) on LTP in the amygdala. These results support the conclusion that both COX-2 and NO are involved in the mediation of Ang-(1-7)induced effects in the brain. Thus, there seems to be molecular cross-talk between the inflammatory mediators COX-2 and NO, with an up-regulation of NO synthesis in homozygous COX-2 knockout mice.

However, wild-type and homozygous COX-2-deficient mice did not show significant changes in response to low-frequency stimulation of external capsule fibers. Therefore, inhibition of COX-2 activity will negatively regulate LTP in the amygdala, but has no effect on LFS-induced activity. It is important that we (Kaschel et al. 2004) and others (Heinbockel and Pape 2000) have demonstrated that neither LFS nor theta pulse stimulation is able to induce LTD in LA neurons of normal rats when stimulating external capsule fibers. However, Ang-(1-7) caused stable LFSinduced LTD in homozygous COX-2 knockout mice, whereas it had no effect in slices derived from wild-type mice. We know from previous studies that SNAP enhances NO concentration in brain slices (Schuchmann et al. 2002). In accordance with our hypothesis that an up-regulation of the NO system occurs in homozygous COX-2 mice, SNAP caused weak, but reliable LFSinduced LTD in wild-type mice. Thus, we show that an upregulation of NO synthesis caused plasticity changes in the lateral amygdala. Our results also support recent findings that NO signaling is an important component of memory formation of auditory fear conditioning (Schafe et al. 2005). 
In summary, a deficiency of COX results in both beneficial and detrimental physiological conditions relative to imbalances of the eicosanoids. Thus, research of the COX pathway is essential to an understanding of COX deficiency, and examining the variable effects of COX inhibition is advantageous.

\section{Materials and Methods}

\section{Animals}

Eight- to 12-wk-old male COX-2-deficient (COX-2 $2^{+/-}$and COX$2^{-/-}$) and wild-type (SV129/C57BL/6 $6^{+/+}$) mice were derived from Taconic. Four mice per cage were kept under standardized conditions with an artificial 12-h dark-light cycle and a room temperature of $22^{\circ} \mathrm{C}$. They had free access to food and water. All experimental protocols were approved by government authorities and conformed to the European Council Directive. The experimenter was blind to the genotype of each mouse, and experiments were randomized with respect to the different groups of animals on a day-to-day basis.

\section{Preparation and recording}

Detailed methods for slice preparation and position of the electrodes have been previously described and are provided here in brief (Drephal et al. 2006). The mice were anesthetized with isoflurane and decapitated. For extracellular recordings, the brains were removed quickly and placed in ice-cold artificial CSF (ACSF) $\left(129 \mathrm{mM} \mathrm{NaCl}, 3 \mathrm{mM} \mathrm{KCl}, 21 \mathrm{mM} \mathrm{NaHCO}{ }_{3}, 1.25 \mathrm{mM} \mathrm{Na}_{2} \mathrm{HPO}_{4}\right.$, $1.8 \mathrm{mM} \mathrm{MgSO}_{4}, 1.6 \mathrm{mM} \mathrm{CaCl}_{2}, 10 \mathrm{mM}$ glucose). Hemisected horizontal slices $(400 \mu \mathrm{m})$ were prepared with a vibroslicer (Campden Instruments). The appropriate slices were placed in an interface chamber and allowed to equilibrate for $120 \mathrm{~min}$ at $35^{\circ} \mathrm{C}$. They were superfused continuously with ACSF $(1.5 \mathrm{~mL} /$ $\mathrm{min}$ ). The $\mathrm{pH}$ was maintained at 7.4 by oxygenating and carbogenating the solution with $95 \% \mathrm{O}_{2}$ and $5 \% \mathrm{CO}_{2}$.

Glass microelectrodes (Science Products) were filled with ACSF (tip resistances $1 \mathrm{M} \Omega$ ) and placed in the caudoventral part of the LA to record field potentials. Bipolar stimulation electrodes were used to stimulate afferents running through the external capsule. Single or paired stimuli (duration $100 \mu \mathrm{sec}$ ) were presented every $10 \mathrm{sec}$. Signals of the evoked responses were amplified and filtered (bandpass, $0.1 \mathrm{~Hz}$ to $3 \mathrm{kHz}$ ) by a preamplifier (World Precision Instruments), displayed on a storage oscilloscope, and fed via a CED laboratory interface (Cambridge Electronic Design) to a computer for storage.

\section{Stimulation parameters}

An input/output (I/O) response curve was constructed by varying the intensity of single-pulse stimulation and averaging six responses to each intensity. Different stimulus intensities were used. The stimulus intensity that evoked field potential amplitude equal to $50 \%$ of the maximal response was then used for all subsequent stimulations, that is, paired-pulse, tetanus (HFS), lowfrequency stimulation (LFS), and subsequent single-pulse stimulations.

To evaluate short-term synaptic interactions, paired-pulse stimuli were delivered with interstimulus intervals ranging from 10 to $500 \mathrm{msec}$. Six consecutive impulses were averaged off-line for each interval. The relative amplitude of the second with respect to the first response amplitude was calculated and plotted as a paired-pulse ratio against the interstimulus interval.

Following paired-pulse stimulation, single stimuli were applied for at least $30 \mathrm{~min}$, and responses were monitored. Once a stable baseline of responses had been obtained for at least 20 min, either high-frequency stimulation (HFS) was delivered as two trains at $100 \mathrm{~Hz}$ (duration $1 \mathrm{sec}, 30 \mathrm{sec}$ apart) or LFS (1 Hz for $15 \mathrm{~min}$ ). Subsequent responses to single stimuli were recorded for at least $60 \mathrm{~min}$, and their amplitudes quantified as percent change with respect to baseline.

\section{Drug application}

In drug-treated slices, HFS or LFS was induced 30 min after perfusing the slices with drugs. We alternated between the control and treatment experiments reported in each figure to account for potential day-to-day as well as time-of-day differences. Ang-(1-7) $(0.01 \mu \mathrm{M}, 0.5 \mu \mathrm{M}, 5 \mu \mathrm{M})$ and A779 $(0.025 \mu \mathrm{M})$ were obtained from Bachem. The COX-2-specific inhibitor $N$-[2-cyclohexyloxy4-nitrophenyl]-methanesulfonamide (NS-398) (Tocris Bioscience) was used in a concentration of $10 \mu \mathrm{M}$. In some experiments L-NAME ( $N$-nitro-L-arginine methyl ester, $200 \mu \mathrm{M}$; Sigma) was used to investigate the influence of inhibition on NO production in the slices. NO donor SNAP ( $S$-nitroso- $N$-acetylpenicillamine; Tocris Bioscience) was applied in concentrations of $100 \mu \mathrm{M}$ in agreement with our previous results (Schuchmann et al. 2002). Application of $1 \mathrm{mM}$ SNAP has been shown to increase the NO concentration in a solution to $\sim 0.5 \mu \mathrm{M}$ for at least $20 \mathrm{~min}$ (Brorson et al. 1999). Therefore, incubation with SNAP concentrations of $100 \mu \mathrm{M}$ will correspond to $\sim 50 \mathrm{nM}$ NO.

Because all substances were washed in by perfusion, they were transported over a certain distance in tubes before they reached the incubation chamber. Therefore, a certain concentration of the substance may adhere to the tubes or will be degraded during transport. Previous studies have shown that equilibration would take a long time and that after 30 min only $30 \%$ of the

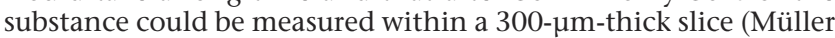
et al. 1988).

\section{Data analysis}

Data were collected and averaged with the custom-made software Signal 2 (Cambridge Electronic Design). The amplitude of field potentials evoked by stimulation of external capsule fibers was observed online, but later reanalyzed offline. We defined the field potential amplitude as the absolute DC voltage of a vertical line running from the minima point of the field potential to its intersection with a line running tangent to the points of field potential onset and offset. The significance of differences within groups was calculated by a Wilcoxon test. The significance of differences between groups was calculated by a Mann-Whitney test (Software GraphPad Prism 4). $P<0.05$ was considered significant. To express and compare changes in field potential amplitude between the animal groups, we averaged responses from the 55-60 min period after HFS.

\section{Acknowledgments}

The invaluable contribution of Karin Berlin and Roland Schneider is gratefully acknowledged. We also thank H. Siegmund for his expert help in data analysis.

\section{References}

Albrecht, D., Nitschke, T., and von Bohlen und Halbach, O. 2000. Various effects of angiotensin II on amygdaloid neuronal activity in normotensive control and hypertensive transgenic [TGR(mREN-2)27] rats. FASEB J. 14: 925-931.

Andreasson, K.I., Savonenko, A., Vidensky, S., Goellner, J.J., Zhang, Y., Shaffer, A., Kaufmann, W.E., Worley, P.F., Isakson, P., and Markowska, A.L. 2001. Age-dependent cognitive deficits and neuronal apoptosis in cyclooxygenase-2 transgenic mice. J. Neurosci. 21: 8198-8209.

Arima, S. and Ito, S. 2001. New insights into actions of the renin-angiotensin system in the kidney: Concentrating on the Ang II receptors and the newly described Ang-(1-7) and its receptor. Semin. Nephrol. 21: 535-543.

Armstrong, D.L., Garcia, E.A., Ma, T., Quinones, B., and Wayner, M.J. 1996. Angiotensin-II blockade of long-term potentiation at the perforant path-granule cell synapse in-vitro. Peptides 17: 689-693.

Bidmon, H.J., Oermann, E., Schiene, K., Schmitt, M., Kato, K., Asayama, K., Witte, O.W., and Zilles, K. 2000. Unilateral upregulation of cyclooxygenase- 2 following cerebral, cortical photothrombosis in the rat: Suppression by MK-801 and co-distribution with enzymes involved in the oxidative stress cascade. J. Chem. Neuroanat. 20: $163-176$.

Bittner, K. and Muller, W. 1999. Oxidative downmodulation of the transient K-current I-A by intracellular arachidonic acid in rat hippocampal neurons. J. Neurophysiol. 82: 508-511.

Brorson, J.R., Schumacker, P.T., and Zhang, H. 1999. Nitric oxide acutely inhibits neuronal energy production. J. Neurosci. 19: $147-158$. 
Brosnihan, K.B. 1998. Effect of the angiotensin-(1-7) peptide on nitric oxide release. Am. J. Cardiol. 82 (Suppl 10A): 17S-19S.

Caggiano, A.O., Breder, C.D., and Kraig, R.P. 1996. Long-term elevation of cyclooxygenase-2, but not lipoxygenase, in regions synaptically distant from spreading depression. J. Comp. Neurol. 376: 447-462.

Chen, C., Magee, J.C., and Bazan, N.G. 2002. Cyclooxygenase-2 regulates prostaglandin E2 signaling in hippocampal long-term synaptic plasticity. J. Neurophysiol. 87: 2851-2857.

Denny, J.B., Polan Curtain, J., Wayner, M.J., and Armstrong, D.L. 1991 Angiotensin II blocks hippocampal long-term potentiation. Brain Res. 567: 321-324.

deOlmos, J.S., Alheid, G.F., and Beltramino, C.A. 1985. Amygdala. In The rat nervous system (ed. G. Paxinos), pp. 223-334. Academic Press, Sydney, Australia.

Drephal, C., Schubert, M., and Albrecht, D. 2006. Input-specific long-term potentiation in the rat lateral amygdala of horizontal slices. Neurobiol. Learn. Mem. 85: 272-282.

Feng, Z., Li, D., Fung, P.C., Pei, Z., Ramsden, D.B., and Ho, S.L. 2003 COX-2-deficient mice are less prone to MPTP-neurotoxicity than wild-type mice. Neuroreport 14: 1927-1929.

Giovannini, M.G., Scali, C., Prosperi, C., Bellucci, A., Pepeu, G., and Casamenti, F. 2003. Experimental brain inflammation and neurodegeneration as model of Alzheimer's disease: Protective effects of selective COX-2 inhibitors. Int. J. Immunopathol. Pharmacol. 16: $31-40$.

Hashimoto, K., Watanabe, K., Nishimura, T., Iyo, M., Shirayama, Y., and Minabe, Y. 1998. Behavioral changes and expression of heat shock protein hsp-70 mRNA, brain-derived neurotrophic factor mRNA, and cyclooxygenase- 2 mRNA in rat brain following seizures induced by systemic administration of kainic acid. Brain Res. 804: 212-223.

Heinbockel, T. and Pape, H.C. 2000. Input-specific long-term depression in the lateral amygdala evoked by theta frequency stimulation. $J$. Neurosci. 20: RC68.

Hellner, K., Walther, T., Schubert, M., and Albrecht, D. 2005. Angiotensin-(1-7) enhances LTP in the hippocampus through the G-protein-coupled receptor Mas. Mol. Cell. Neurosci. 29: 427-435.

Ho, L., Qin, W., Stetka, B.S., and Pasinetti, G.M. 2006. Is there a future for cyclo-oxygenase inhibitors in Alzheimer's disease? CNS Drugs 20: $85-98$.

Humeau, Y., Shaban, H., Bissiere, S., and Luthi, A. 2003. Presynaptic induction of heterosynaptic associative plasticity in the mammalian brain. Nature 426: $841-845$.

Johnson, A.K. and Thunhorst, R.L. 1997. The neuroendocrinology of thirst and salt appetite: Visceral sensory signals and mechanisms of central integration. Front. Neuroendocrinol. 18: 292-353.

Kaschel, T., Schubert, M., and Albrecht, D. 2004. Long-term depression in horizontal brain slices of the lateral amygdala. Synapse 53: $141-150$.

Kaufmann, W.E., Worley, P.F., Pegg, J., Bremer, M., and Isakson, P. 1996. COX-2, a synaptically induced enzyme, is expressed by excitatory neurons at postsynaptic sites in rat cerebral cortex. Proc. Natl. Acad. Sci. 93: 2317-2321.

Miettinen, S., Fusco, F.R., Yrjanheikki, J., Keinanen, R., Hirvonen, T. Roivainen, R., Narhi, M., Hokfelt, T., and Koistinaho, J. 1997. Spreading depression and focal brain ischemia induce cyclooxygenase- 2 in cortical neurons through N-methyl-D-aspartic acid-receptors and phospholipase A2. Proc. Natl. Acad. Sci. 94: 6500-6505.

Mollace, V., Muscoli, C., Masini, E., Cuzzocrea, S., and Salvemini, D. 2005. Modulation of prostaglandin biosynthesis by nitric oxide and nitric oxide donors. Pharmacol. Rev. 57: 217-252.

Müller, W., Misgeld, U., and Heinemann, U. 1988. Carbachol effects on hippocampal neurons in vitro: Dependence on the rate of the rise of carbachol tissue concentration. Exp. Brain Res. 72: 287-298.

Murray, H.J. and O'Connor, J.J. 2003. A role for COX-2 and p38 mitogen activated protein kinase in long-term depression in the rat dentate gyrus in vitro. Neuropharmacology 44: 374-380.

Muthalif, M.M., Benter, I.F., Uddin, M.R., Harper, J.L., and Malik, K.U. 1998. Signal transduction mechanisms involved in angiotensin-(1-7)-stimulated arachidonic acid release and prostanoid synthesis in rabbit aortic smooth muscle cells. J. Pharmacol. Exp. Ther. 284: 388-398.
O'Banion, M.K. 1999. COX-2 and Alzheimer's disease: Potential roles in inflammation and neurodegeneration. Expert Opin. Investig. Drugs 8: $1521-1536$

Rall, J.M., Mach, S.A., and Dash, P.K. 2003. Intrahippocampal infusion of a cyclooxygenase- 2 inhibitor attenuates memory acquisition in rats. Brain Res. 968: 273-276.

Salvemini, D., Misko, T.P., Masferrer, J.L., Seibert, K., Currie, M.G., and Needleman, P. 1993. Nitric oxide activates cyclooxygenase enzymes. Proc. Natl. Acad. Sci. 90: 7240-7244.

Santos, R.A., Campagnole-Santos, M.J., Baracho, N.C., Fontes, M.A., Silva, L.C., Neves, L.A., Oliveira, D.R., Caligiorne, S.M., Rodrigues, A.R., and Gropen, J.C. 1994. Characterization of a new angiotensin antagonist selective for angiotensin-(1-7): Evidence that the actions of angiotensin-(1-7) are mediated by specific angiotensin receptors. Brain Res. Bull. 35: 293-298.

Santos, R.A., Campagnole-Santos, M.J., and Andrade, S.P. 2000. Angiotensin-(1-7): An update. Regul. Pept. 91: 45-62.

Schafe, G.E., Bauer, E.P., Rosis, S., Farb, C.R., Rodrigues, S.M., and LeDoux, J.E. 2005. Memory consolidation of Pavlovian fear conditioning requires nitric oxide signaling in the lateral amygdala. Eur. J. Neurosci. 22: 201-211.

Schuchmann, S., Albrecht, D., Heinemann, U., and Bohlen und Halbach, O. 2002. Nitric oxide modulates low- $\mathrm{Mg}^{2+}$-induced epileptiform activity in rat hippocampal-entorhinal cortex slices. Neurobiol. Dis. 11: 96-105.

Slanina, K.A., Roberto, M., and Schweitzer, P. 2005. Endocannabinoids restrict hippocampal long-term potentiation via CB1. Neuropharmacology 49: 660-668.

Stellar, E. 1993. Salt appetite: Its neuroendocrine basis. Acta Neurobiol. Exp. (Wars.) 53: 475-484

Takemiya, T., Suzuki, K., Sugiura, H., Yasuda, S., Yamagata, K., Kawakami, Y., and Maru, E. 2003. Inducible brain COX-2 facilitates the recurrence of hippocampal seizures in mouse rapid kindling. Prostaglandins Other Lipid Mediat. 71: 205-216.

Teather, L.A., Packard, M.G., and Bazan, N.G. 2002. Post-training cyclooxygenase-2 (COX-2) inhibition impairs memory consolidation. Learn. Mem. 9: 41-47.

Tsvetkov, E., Carlezon, W.A., Benes, F.M., Kandel, E.R., and Bolshakov, V.Y. 2002. Fear conditioning occludes LTP-induced presynaptic enhancement of synaptic transmission in the cortical pathway to the lateral amygdala. Neuron 34: 289-300.

Vane, J.R., Bakhle, Y.S., and Botting, R.M. 1998. Cyclooxygenases 1 and 2. Annu. Rev. Pharmacol. Toxicol. 38: 97-120.

Vaughan, C.W. 1998. Enhancement of opioid inhibition of GABAergic synaptic transmission by cyclo-oxygenase inhibitors in rat periaqueductal grey neurones. Br. J. Pharmacol. 123: 1479-1481.

Vijitruth, R., Liu, M., Choi, D.Y., Nguyen, X., Hunter, R.L., and Bing, G. 2006. Cyclooxygenase- 2 mediates microglial activation and secondary dopaminergic cell death in the mouse MPTP model of Parkinson's disease. J. Neuroinflammation 3: 6.

von Bohlen und Halbach, O. and Albrecht, D. 1998. Angiotensin II inhibits long-term potentiation within the lateral nucleus of the amygdala through AT1 receptors. Peptides 19: 1031-1036.

von Bohlen und Halbach, O. and Albrecht, D. 2002. Reciprocal connections of the hippocampal area CA1, the lateral nucleus of the amygdala and cortical areas in a combined horizontal slice preparation. Neurosci. Res. 44: 91-100.

von Bohlen und Halbach, O. and Albrecht, D. 2006. The CNS renin-angiotensin system. Cell Tissue Res. 326: 599-616.

Warner, T.D. and Mitchell, J.A. 2004. Cyclooxygenases: New forms, new inhibitors, and lessons from the clinic. FASEB J. 18: 790-804.

Wright, J.W., Reichert, J.R., Davis, C.J., and Harding, J.W. 2002. Neural plasticity and the brain renin-angiotensin system. Neurosci. Biobehav. Rev. 26: 529-552.

Yamagata, K., Andreasson, K.I., Kaufmann, W.E., Barnes, C.A., and Worley, P.F. 1993. Expression of a mitogen-inducible cyclooxygenase in brain neurons: Regulation by synaptic activity and glucocorticoids. Neuron 11: 371-386.

Received September 7, 2006; accepted in revised form January 23, 2007. 


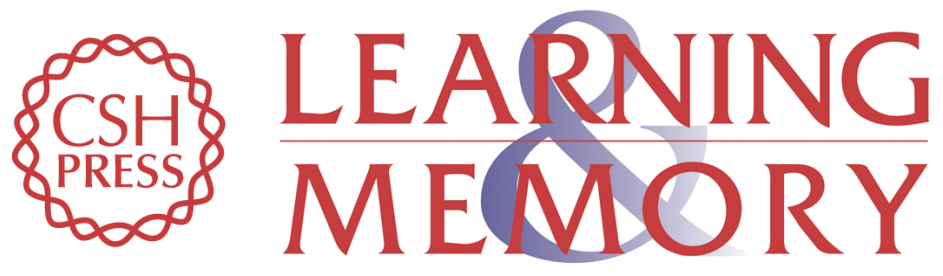

\section{Angiotensin-(1-7)-induced plasticity changes in the lateral amygdala are mediated by COX-2 and NO}

Doris Albrecht

Learn. Mem. 2007, 14:

Access the most recent version at doi:10.1101//m.425907

References This article cites 47 articles, 8 of which can be accessed free at:

http://learnmem.cshlp.org/content/14/3/177.full.html\#ref-list-1

License

Email Alerting Receive free email alerts when new articles cite this article - sign up in the box at the Service top right corner of the article or click here. 